( $p<0.001$ ); however, one S had more errors with the white tray and the other had more errors with the black.

\section{DISCUSSION}

The results show that the squirrel monkey is capable of learning two classical variations of conditional discrimination. The significant interproblem improvement in performance from the two-object to the one-odd conditional discrimination problem suggests that the Ss may have been forming a set to learn (this was corroborated by post hoc training with the same Ss soon after completion of the present experiments on five different two-object conditional discrimination problems; the Ss learned these problems with means of $169,100.5,104.2$, 138.2 , and 189.5 trials to the same criterion as previous problems and $58.2,29,23.5$, 34.8 , and 57.2 mean errors); however, it is possible that the one-odd problem was inherently easier to learn than the twoobject problem.

The analyses of errors as a function of tray brightness suggested that this was a significant factor for some of the monkeys. These findings suggest that the monkeys may have learned parts of the conditional discrimination separately rather than learning the overall concept of the reward contingencies. For example, the data suggest that the white-tray/parallelogram association was learned with significantly fewer errors than the black-tray/cross association.

\section{REFERENCES}

FRENCH, G. M. Associative problems. In A. M. Schrier, H. F. Harlow, and F. Stollnitz (Eds.) Behavior of non-human primates Vol. 1. New York: Academic Press, 1965.

GOLLIN, E. S., \& LISS, P. Conditional discrimination in children. Journal of Comparative \& Physiological Psychology, 1962, 55, 850-855.

JOSHI, B. L., \& WARREN, J. M. Discrimination of ambivalent cue stimuli by cats. Journal of Psy chology, 1955, 47, 3 .

LASHLEY, K. S. Conditional reactions in the rat Journal of Psy chology, 1938, 6, 311-324.

NISSEN, H. W., BLUM, J. S., \& BLUM, R. A. Conditional matching behavior in chimpanzee: Implications for the study of comparative study of intelligence. Journal of Comparative \& Physiological Psychology, 1949, 42, 339-356.

NOER, M. C., \& HARLOW, H. F. Discrimination of ambivalent cue stimuli by macaque monkeys. Journal of General Psychology, 1946, 34, 165-177.

NORTH, A. J., MALLER, O., \& HUGHES, C. Conditional discrimination and stimulus patterning. Joumal of Comparative \& Physiological Psychology, 1958, 51, 711-715.

WOODBURNE, L. S., \& RIEKE, C. K. Response to symbols by squirrel monkeys. Psychonomic Science, $1966,5,429-430$.

$$
\text { NOTES }
$$

1. The present work was based on the MS thesis of the first author at the University of Georgia.

2. Now serving in the U.S. Army. Address reprint requests to the second author.

\title{
Alcohol ingestion without oropharyngeal sensations
}

\section{ZALMAN AMIT and MURIEL H. STERN, McGill University, Montreal, Canada}

Rats pressed a lever significantly more often in the condition of simultaneous presentation of water orally and alcohol by direct infusion to the stomach than in the reverse condition With no oral presentation, Ss pressed significantly oftener for alcohol infusion than for water infusion, suggesting the development of an alcohol preference.

The laboratory rat's well-known reluctance to drink alcohol in high concentrations is usually attributed by research workers to the aversive properties of the taste and smell of alcohol. The evidence for this is inferential, and does not appear to have been demonstrated directly.

The present study was designed to explore the relation between taste and voluntary alcohol ingestion in the rat, by eliminating the oropharyngeal sensations associated with ingestion of alcohol by mouth, while maintaining the voluntary aspects of ingestion. Our objectives were to determine: (a) whether the absence of taste and smell would eliminate the aversion to alcohol and create a preference for it, and (b) if experience with alcohol under such conditions would change subsequent behavior in a free-choice water-alcohol situation.

\section{SUBJECTS}

Subjects were 18 male hooded rats, weighing between $250-275 \mathrm{~g}$ and approximately 100 days old at the beginning of the experiment. All Ss were implanted with an intragastric fistula, following a modification of the method described by Kohn (1951). The tube was brought to the outside of the animal, on top of the head, where it was attached to a syringe needle that was cut $1 / 4$ in. below the female taper and bent to a 90-deg angle. The syringe was then cemented to the skull. Four days after operation, at the beginning of the pretraining period, the Ss were placed on a 22 -h water-deprivation schedule.

\section{APPARATUS}

The apparatus was a single-lever Skinner box, with a liquid dispenser, which delivered $.05 \mathrm{ml}$ of liquid per lever press. The lever also operated a multispeed infusion pump (Multispeed-Transmission, Harvard Co., Dover, Mass.) that was attached to the female taper of the intragastric fistula and was also calibrated

\section{to deliver $.05 \mathrm{ml}$ of liquid.} PROCEDURE

Fourteen of the animals were pretrained to press the lever for water on a continuous reinforcement schedule. The acquisition criterion was 50 lever presses in a 10-min period, on three consecutive daily sessions. The experimental conditions were imposed on the day following criterion performance, and obtained for the following 14 days. Daily experimental sessions were of 12-min duration. During the experimental sessions, the initial lever depression was followed immediately by the presentation of liquid in the dispenser and a simultaneous injection through the infusion pump directly into the stomach. The liquid dispenser then became inoperative, for $3 \mathrm{sec}$, during which time a lever depression resulted only in the operation of the infusion pump and the delivery of fluid into the stomach. One group of animals $(\mathrm{N}=7)$ received $17 \%$ alcohol $(\mathrm{vv})$ in the liquid dispenser and water infused to the stomach, and a second group $(\mathrm{N}=7)$ received water in the liquid dispenser (that is, by mouth) and the $17 \%$ alcohol directly to the stomach. It follows, then, that during the 3-sec period in which the liquid dispenser was inoperative, none of the animals could drink either liquid but seven of them could receive water and seven of them could receive alcohol, infused directly into the stomach. The remaining four animals were not placed in the experimental situation but for the 14 days of the experimental period were given a choice between water and $17 \%$ alcohol for $2 \mathrm{~h}$ per day in their home cages. Following the 14-day experimental period, all 18 animals were maintained on 22 -h water deprivation for 7 days, during which time they were given a free choice of water or $17 \%$ alcohol for a daily $2-h$ period.

\section{RESULTS}

During the 14-day experimental period, Ss that received alcohol by infusion and water by mouth ingested more alcohol than did the Ss that received water by infusion and alcohol by mouth. An analysis of variance revealed that this difference was significant at the .001 level of probability. The difference was reflected in the two measures of rate of lever pressing the study generated: (a) When the liquid dispenser was operating, Ss that received alcohol by infusion and water by mouth pressed the lever at a rate consistently higher than than of the Ss that received 

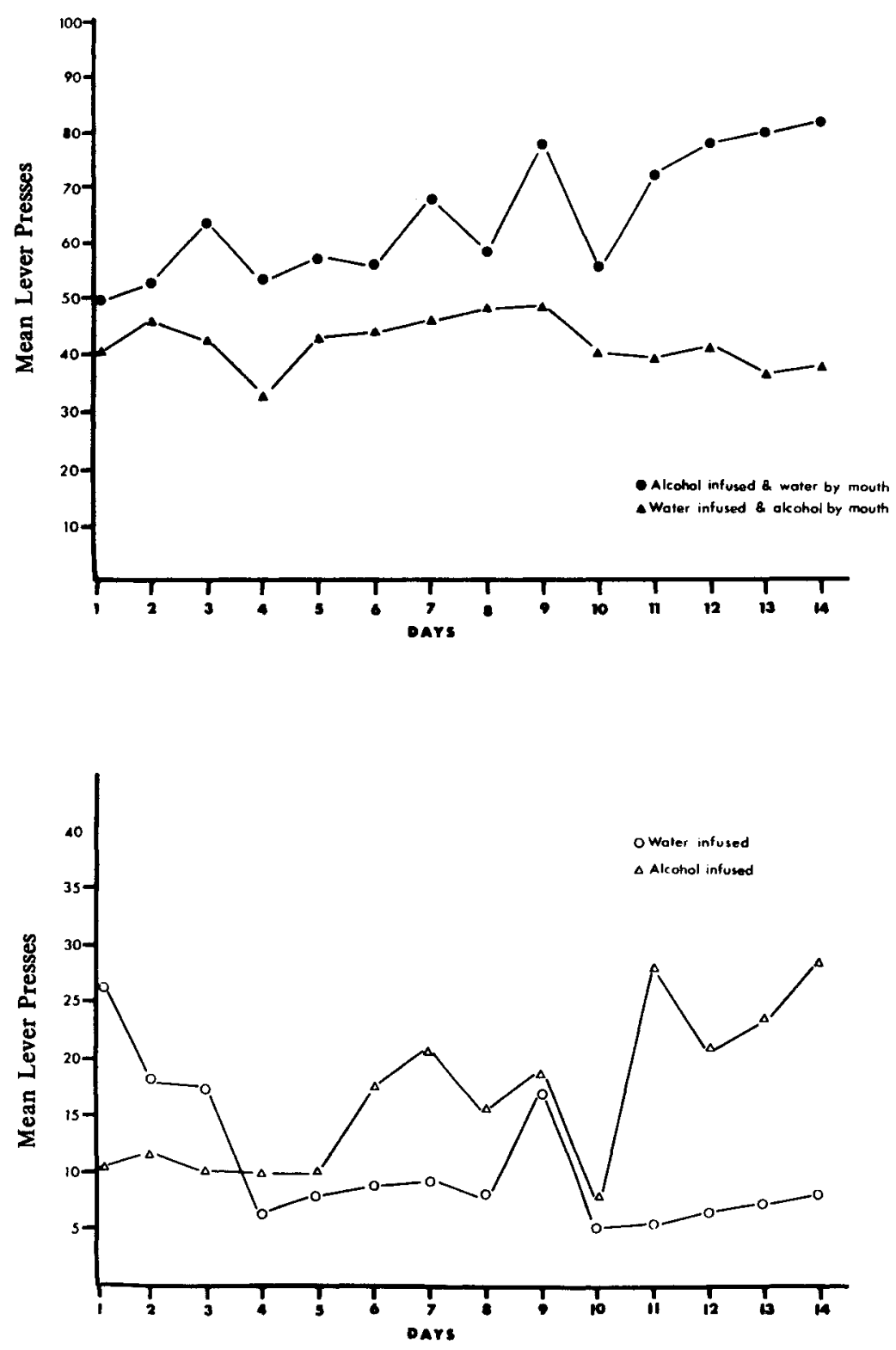

Fig. 1. (a) Both liquid dispenser and infusion pump are operative; (b) only infusion pump is operative.

alcohol by mouth and water by infusion.

(b) When the liquid dispenser was not

operating, and liquid could be delivered only directly into the stomach, Ss of both groups were pressing the lever at approximately the same rate for the first 10 days of the experimental period. From Days 11 to 14, however, the pressing rate of the animals who received alcohol by infusion was significantly higher $(p=.01)$ than that of the other group. Thus, by the end of the experimental period, the group that was receiving alcohol without the experience of oropharangeal sensations was pressing the lever at a consistently higher rate during both periods. During the subsequent 7 days, there were no significant differences between groups when alcohol ingestion was measured in the free-choice drinking periods.

\section{DISCUSSION}

Under the conditions of the present experiment, laboratory rats ingested large quantities of an alcohol solution that is usually deemed to be aversive. This finding is consistent with that of Borer \& Epstein (1965) who found that the aversive properties of concentrated $\mathrm{NaCl}$ solution are eliminated under conditions of intragastric infusion. Unlike the Ss of Borer and Epstein's experiment, however, the animals in our study ingested not approximately equal amounts of water and alcohol, but significantly greater amounts of alcohol than water. In addition, when there was no oral presentation of either water or alcohol, and the animals' lever presses resulted only in intragastric infusion, our Ss showed a significant preference for alcohol. This preference was not maintained in the home cages in the postexperimental period. The possibility that longer daily experimental sessions and a more lengthy experimental period would have more permanent effects on alcohol-water preference remains to be investigated.

\section{REFERENCES}

BORER, K. T \& EPSTEIN, A. N. Disappearance of salt and sweet preference in rats drinking without taste and smell. Physiologist, 1965, 8, No. 3.

KOHN, M. Satiation of hunger from stomach versus mouth feeding. Journal of Comparative \& Physiological Psychology, 1951, 44, 412-422. 